\title{
Modeling of Solute Transport in a 3D Rough-Walled Fracture-Matrix System
}

\author{
Liangchao Zou $^{1}$ • Lanru Jing $^{1}$ • Vladimir Cvetkovic ${ }^{1}$
}

Received: 16 June 2016 / Accepted: 10 December 2016 / Published online: 21 January 2017

(C) The Author(s) 2017. This article is published with open access at Springerlink.com

\begin{abstract}
Fluid flow and solute transport in a 3D rough-walled fracture-matrix system were simulated by directly solving the Navier-Stokes equations for fracture flow and solving the transport equation for the whole domain of fracture and matrix with considering matrix diffusion. The rough-walled fracture-matrix model was built from laser-scanned surface tomography of a real rock sample, by considering realistic features of surfaces roughness and asperity contacts. The numerical modeling results were compared with both analytical solutions based on simplified fracture surface geometry and numerical results by particle tracking based on the Reynolds equation. The aim is to investigate impacts of surface roughness on solute transport in natural fracture-matrix systems and to quantify the uncertainties in application of simplified models. The results show that fracture surface roughness significantly increases heterogeneity of velocity field in the rough-walled fractures, which consequently cause complex transport behavior, especially the dispersive distributions of solute concentration in the fracture and complex concentration profiles in the matrix. Such complex transport behaviors caused by surface roughness are important sources of uncertainty that needs to be considered for modeling of solute transport processes in fractured rocks. The presented direct numerical simulations of fluid flow and solute transport serve as efficient numerical experiments that provide reliable results for the analysis of effective transmissivity as well as effective dispersion coefficient in rough-walled fracture-matrix systems. Such analysis is helpful in model verifications, uncertainty quantifications and design of laboratorial experiments.
\end{abstract}

Keywords Solute transport · Fracture surface roughness · Fracture-matrix system · Matrix diffusion · Contact spots

Liangchao Zou

1zo@kth.se

1 Division of Land and Water Resources Engineering, Department of Sustainable Development, Environmental Science and Engineering, Royal Institute of Technology, 10044 Stockholm, Sweden 


\section{Introduction}

Fluid flow and solute transport in fractured crystalline rocks are crucial issues in many branches of geosciences and rock engineering projects, such as risk and safety assessment of groundwater contamination, reservoir storage, geothermal extraction, geological disposal of radioactive waste and carbon dioxide. Modeling and quantification of flow and transport in discrete fracture-matrix system is one of the basic ways to advance our fundamental understanding of transport processes in natural fractured rocks (Zimmerman and Bodvarsson 1996; Bodin et al. 2003a).

In past decades, analytical and semi-analytical solutions have been developed to predict solute transport through a single fracture contained in porous media or rock matrixes (fracture-matrix system), such as Neretnieks (1980), Tang et al. (1981), Sudicky and Frind (1982), Abdel-Salam and Chrysikopoulos (1994), Cvetkovic et al. (1999), Zhan et al. (2009), Liu et al. (2011), Roubinet et al. (2012). Tang et al. (1981) and Sudicky and Frind (1982) that were the earliest deduced widely used analytical solutions for modeling solute transport in fracture-matrix models. In these analytical solutions, the fracture was assumed to be a pair of smoothed parallel plates with a constant aperture and a constant flow velocity derived from the cubic law (CL). Such a much simplified system was composed of two sub-models in a 2D space: a one-dimensional fracture model inserted into a twodimensional matrix model with solute transport only in the direction perpendicular to the fracture plane. These analytical solutions have been extensively used and extended in modeling the solute/contaminant transport processes of fractured rock systems (e.g., Liu et al. 2011; Zhao et al. 2011).

Natural rock fractures are formed by two rough-walled surfaces. Therefore, rock fractures have spatially variable apertures and asperity contacts, which can be enhanced by mechanical loading (i.e., shear and compression processes). The surface roughness and associated spatially variable apertures significantly enhance the complexity of flow fields or even cause nonlinear flow behaviors, depending on the hydrogeological and hydromechanical conditions, or laboratory test designs, which has been widely investigated in previous studies (e.g., Zimmerman et al. 2004; Boutt et al. 2006; Cardenas et al. 2007; Lee et al. 2014, 2015; Zou et al. 2015). Thus, the uncertainties caused by laminar and constant flow simplifications adopted in analytical solutions for modeling of solute transport in natural fractured rocks need to be quantified, since the flow velocity was directly connected with advection and dispersion processes of solute transport. In addition, the non-planar interfaces between rough-walled fracture and rock matrix play significant roles in fluid/solute-matrix interactions, such as matrix diffusion, surface sorption and chemical reactions (Bodin et al. 2003a, b). Therefore, it is quite important to quantify impacts of surface roughness on fluid flow and solute transport in fracture-matrix systems.

Due to difficulties in direct measurements during field or laboratory experiments with complex flow field in rough-walled fractures, numerical models have been developed to investigate effects of fracture surface roughness on solute or colloid transport in single roughwalled fractures, e.g., by Moreno et al. (1988), Thompson and Brown (1991), Moreno and Neretnieks (1993), Abdel-Salam and Chrysikopoulos (1995), Yeo (2001), Chrysikopoulos and James (2003), Cardenas et al. (2007), and Wang and Cardenas (2014). These studies generally illustrated the importance of surface roughness on flow and transport process. However, most of these studies still used simplified models by ignoring nonlinear/inertial terms in governing equations (i.e., using the Stokes or Reynolds equations) and adopting 2D geometry models (e.g., Moreno and Neretnieks 1993; Yeo 2001; Chrysikopoulos and James 
2003; Wang and Cardenas 2014), so the realistic flow behavior in natural fractures cannot be adequately represented; therefore, the more general governing equation of flow, NavierStokes equations (NSE), and 3D models should be adopted. At present, direct simulations by solving NSE for 3D fractures with complex surface geometry still demand challenging computational resources and efforts. Only few studies successfully implemented direct modeling of flow and transport in rock fractures in 3D spaces (e.g., Zimmerman et al. 2004; Crandall et al. 2010; Xiong et al. 2011; Wang et al. 2015), with focuses on flow and/or transport in the fracture only, and the effects of interactions between fracture and the rock matrix on solute transport were neglected.

In order to consider the matrix diffusion, Grisak and Pickens (1980) simulated the solute transport in a single fracture-matrix system model in 2D by using the finite element method. However, the fracture was still assumed as the smooth parallel plate model and the flow field was also obtained by using cubic law, so that roughness of fracture surfaces and related complex flow behaviors were ignored. Numerical studies reported in Kennedy and Lennox (1995), Esposito and Thomson (1999), Kumar (2008) and Renu and Kumar (2012) followed the same assumptions as adopted in analytical models that separately solve the transport equation in the fracture and matrix system, through a combined stepwise procedure. The most challenging issues in such modeling approaches are the difficulties in treatment of 'interfacial boundary' conditions between the matrix and fracture along the fracture surfaces, since the requirement of consistency of solute flux across the interface from the fracture into the matrix cannot be treated properly, which usually need massive iteration steps in the solution process. More importantly, such numerical models are still based on the same assumptions as adopted in the analytical models.

In order to advance our understanding of solute transport in natural fractured rocks with more realistic representations of fracture surface roughness and asperity contacts/closures, direct simulation of flow and transport processes in whole fracture-matrix systems in 3D is required. To fill this gap, we present in this study with direct simulations of fluid flow and solute transport within a 3D rough-walled fracture-matrix model, which was built from laser-scanned surface tomography of a real rock sample. The aim is to investigate impacts of surface roughness on solute transport in natural fracture-matrix systems and to quantify the uncertainties in applications of simplified models based on simplified geometry and/or flow conditions. More realistic flow fields were obtained by directly solving the Navier-Stokes equations (NSE) in the fracture with realistic surfaces roughness, as well as shear caused fracture contacts. The general transport equation that accounts for advection and diffusion in the entire fracture-matrix system was also directly solved simultaneously, in order to avoid the difficulty in treatment of 'interfacial boundary' conditions.

The originality of this study lies in two aspects: (1) direct simulation of fluid flow and solute transport in a 3D rough-walled fracture-matrix system, representing realistic features of fracture surface roughness and contacts, a relatively more realistic numerical experiment that have not been reported in literature so far; and (2) comparing numerical modeling results with classical analytical solution, so that the impacts of fracture surface roughness whereby associated uncertainties can be demonstrated and quantified to a conceptual extent, since measured data from reliable laboratory experiments for the fracture-matrix systems are still unavailable at present. The results of this study would help to evaluate uncertainties in modeling of mass and heat transport in fractured rocks, especially when the simplified models are used in practical applications. 

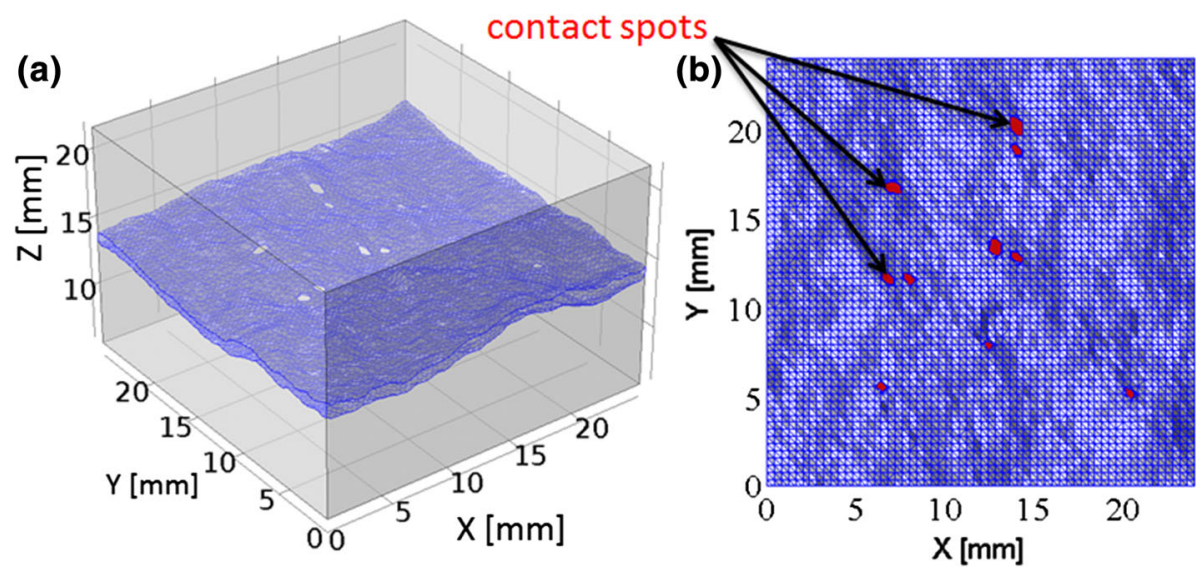

Fig. 1 a Rough-walled fracture-matrix model and $\mathbf{b}$ top view of fracture model

\section{Fracture-Matrix Model and Physical Considerations}

\subsection{Fracture-Matrix System}

In this study, we consider a rough-walled fracture located in a fully saturated porous crystalline rock matrix of very low permeability, such as granite, as shown in Fig. 1a. The size of the fracture-matrix model is $24.8 \mathrm{~mm}$ in length, $24.8 \mathrm{~mm}$ in width and $16 \mathrm{~mm}$ in height. A fracture comprised of two rough-walled surfaces in the middle of the model (in blue color) was created by using a laser-scanned natural granite rock fracture surface (Koyama et al. 2008; Zou et al. 2015). Specifically, this fracture model was built by a numerical 'uplift' step that simply extruded up the laser-scanned surface in the vertical height direction ( $Z$-direction) by $0.65 \mathrm{~mm}$ and then a 'shear' step that shifted the upper surface along the horizontal length direction ( $X$-direction) with a displacement of $1.0 \mathrm{~mm}$ (Zou et al. 2016a). Such steps created a numerical 3D fracture model with spatially variable apertures and several contact spots (highlighted in red in Fig. 1b) formed by the unmatched upper and lower surfaces.

Note that the fracture model created in this way was not from direct shear testing measurements in laboratory. For simplicity, the overlapping parts of asperity tips during the shear step were removed and the potential damaged rocks were ignored. Such damaged asperities and shear caused small particles may also have important effects according to the literature (e.g., Zhao 2013; Neretnieks 2014). Hoverer, it is beyond the scope of the current study. The fracture model created in this study provided a realistic representation of surface roughness in natural rock fractures with contacting asperities and complex space of variable apertures, for a generic study.

\subsection{Physical Considerations}

We consider fluid flow in the fracture and solute transport through the whole fracture-matrix system. The principal fluid flow is along the $Y$ axis direction, and the source of solute with a constant concentration $\left(C_{0}\right)$ was specified on the inlet boundary of the fracture.

The rock matrix concerned is granite in a fully saturated state but with zero velocity due to its low permeability. The fluid concerned is incompressible and Newtonian for simplicity. The shear displacement and contact of asperities represent the effect of mechanical process, 
with change in porosity/permeability by stress in matrix being ignored since such small shear displacement will not cause significant changes in porosity or permeability of the hard crystalline rock concerned.

Bodin et al. (2003a, b) provided a comprehensive review of key physical mechanisms in such fracture-matrix systems, mainly including solute advection and dispersion in the fracture, matrix diffusion from the fracture into the matrix, fracture surface and matrix sorption, decay and chemical reactions. We only consider the advection and dispersion in the fracture, and diffusion in the rock matrix from fracture surfaces for simplicity.

\section{Modeling of Solute Transport in Fracture-Matrix System}

\subsection{Governing Equations and Numerical Method}

The solute transport processes considered in this study through such a fracture-matrix system, as shown in Fig. 1, can be expressed by the general transport equation without source terms, written as

$$
\frac{\partial \theta C}{\partial t}+u \cdot \nabla C-\nabla \cdot \theta D(\nabla C)=0
$$

where $C\left(\mathrm{~kg} / \mathrm{m}^{3}\right), t(\mathrm{~s}), u(\mathrm{~m} / \mathrm{s}), D\left(\mathrm{~m}^{2} / \mathrm{s}\right)$ and $\theta$ denote the volumetric solute concentration in fluid phase, the time, the fluid velocity, the dispersion coefficient and the rock matrix porosity, respectively. For the fracture, with accurate velocity field by solving NSE, its dispersion coefficient $D$ is the molecular diffusion coefficient $D^{*}$ of solute in the fracture fluid (i.e., water), expressed as $D=D^{*}$.

For the porous rock matrix, the diffusion coefficient is equal to the effective diffusion coefficient, and it was defined as related to the matrix tortuosity $(\tau)$, written as $D=\tau D^{*}$ (Tang et al. 1981; Sudicky and Frind 1982). Alternative definition of effective diffusion coefficient is based on the well-known Archie's law.

For the transport, no solute was assumed in the entire fracture-matrix system initially $(C=0$ at $t=0)$. All boundaries were set as gradient free of concentration $(\boldsymbol{n} \cdot \nabla C=0$, where $\boldsymbol{n}$ is normal vector of boundary), except the inlet boundary of the fracture, where the boundary condition was set as constant concentration $\left(C=C_{0}\right)$.

For the isothermal, steady-state and incompressible single Newtonian fluid flow in the fracture, the governing equations are the NSE, which represents mass and momentum conservations, written as

$$
\begin{aligned}
& \nabla \cdot \boldsymbol{u}=0 \\
& \rho \boldsymbol{u} \cdot \nabla \boldsymbol{u}-\mu \nabla^{2} \boldsymbol{u}=-\nabla P
\end{aligned}
$$

where $\rho\left(\mathrm{kg} / \mathrm{m}^{3}\right), \boldsymbol{u}(\mathrm{m} / \mathrm{s}), P(\mathrm{~Pa}), \mu(\mathrm{Pa} \cdot \mathrm{s})$ and $t(\mathrm{~s})$ denote the density of a fluid, the velocity vector, the pressure, the viscosity coefficient and time, respectively.

The inlet boundary for flow in the fracture was given as flowrate, such that the flow is free to enter into the rock fracture depending on local apertures of the inlet surface, which can reduce the boundary effects. The outlet boundary of flow was set as zero pressure $(P=0)$. The rest of fracture surfaces were set as sealed non-slip walls $(\boldsymbol{u}=0)$.

The transport equation and NSE are a set of nonlinear partial differential equations coupled with velocity, pressure and concentration fields. In this study, the commercial finite element software of COMSOL Multiphysics 5.1 was employed to sequentially solve the NSE and transport equations (COMSOL 2016). 


\subsection{Analytical Solution for the Simplified Fracture-Matrix System}

In order to compare the numerical results obtained from this study with widely used analytical solution for simplified geometry model without considering the surface roughness, the classical analytical solution by Sudicky and Frind (1982) was simply introduced as follows.

In this analytical solution (Sudicky and Frind 1982), the general transport equation (Eq. 1) for the whole domain of the fracture-matrix system was written as two one-dimensional separate transport equations: one for the fracture and another for the matrix, written as

$$
\begin{aligned}
& \frac{\partial C_{f}}{\partial t}+u \frac{\partial C_{f}}{\partial x}-D_{f} \frac{\partial^{2} C_{f}}{\partial x^{2}}-\left.\frac{\theta D_{m}}{b} \frac{\partial C_{m}}{\partial z}\right|_{z= \pm b}=0 \\
& \frac{\partial C_{m}}{\partial t}-D_{m} \frac{\partial^{2} C_{m}}{\partial z^{2}}=0
\end{aligned}
$$

where $C_{f}, C_{m}$ and $D_{f}, D_{m}$ are the concentrations and dispersion/diffusion coefficients in the fracture and matrix, respectively. The symbol $u$ is the constant velocity in fracture, $\mathrm{b}$ is half aperture, $\theta$ is porosity of matrix, $t$ is time, and $X$ and $z$ are the spatial coordinates in flow and vertical directions, respectively. Since the flow velocity in the fracture was assumed as constant in this analytical model, the fracture dispersion coefficient was defined as

$$
D_{f}=\alpha_{L} u+D^{*}
$$

where $\alpha_{L}(\mathrm{~m})$ is the longitudinal dispersivity.

The closed-form solution was deduced through the Laplace transform approach. The detailed solution and procedures can be found in Sudicky and Frind (1982). Note that this analytical model in Sudicky and Frind (1982) is in the same framework of assumptions used in Tang et al. (1981), as discussed in Zou et al. (2016b). The difference in Sudicky and Frind (1982) is that the boundary conditions of the bounded matrix were set as concentration gradient free, $\frac{\partial C_{m}}{\partial z}(x, z= \pm B, t)=0$, where the $B$ is the matrix thickness, instead of zero concentration $C_{m}(x, z=\infty, t)=0$ for the infinite matrix domain used in Tang et al. (1981). Such gradient free boundary condition on the matrix represents the case of transport in a system of discrete multiple-parallel fractures, with the finite intervening porous matrix. It is also consistent with the numerical models in this study within a finite matrix domain.

\section{Simulation Results}

\subsection{Simulation Settings}

The established fracture-matrix system model was discretized into 3.7 million tetrahedral elements. Special finer elements (around $0.05 \mathrm{~mm}$ ) were used for the fracture part (especially near the asperity contacts) to properly represent the complex geometry of surface roughness. The resolution of meshes was determined through a mesh-size sensitivity analysis procedure, to reach mesh-independency condition and numerical stability of the simulation results.

A constant solute concentration $C_{0}\left(\mathrm{~kg} / \mathrm{m}^{3}\right)$ was injected on the origin of fracture (inlet boundary of the fracture) for transport simulations. For convenient comparison of results, the concentration was normalized as $C^{\prime}=C / C_{0}$. Unless specified otherwise, the results reported below used the normalized time as $t^{\prime}=t / \bar{t}$ for comparison, where $\bar{t}$ is the mean residence time for fluid flow through the fracture $(\bar{t}=L / u$, where $L$ is the length of fracture and $u$ is the averaged flow velocity in the fracture in the $Y$ direction). 
Table 1 Parameters and boundary conditions adopted for simulations

\begin{tabular}{lll}
\hline Parameter & Note (unit) & Value \\
\hline Gravitational acceleration & $g\left(\mathrm{~m} / \mathrm{s}^{2}\right)$ & 9.8 \\
Water density & $\rho\left(\mathrm{kg} / \mathrm{m}^{3}\right)$ & $9.997 \mathrm{e} 2$ \\
Water viscosity & $\mu(\mathrm{Pa} \cdot \mathrm{s})$ & $1.307 \mathrm{e}-3$ \\
Diffusion coefficient & $\mathrm{D}^{*}\left(\mathrm{~m}^{2} / \mathrm{s}\right)$ & $2.03 \mathrm{e}-9$ \\
Rock matrix porosity & $\theta(-)$ & 0.01 \\
Rock matrix tortuosity & $\tau(-)$ & 0.1 \\
Injection concentration & $C_{0}\left(\mathrm{~kg} / \mathrm{m}^{3}\right)$ & 1.0 \\
Inlet flowrate & $Q\left(\mathrm{~m}^{3} / \mathrm{s}\right)$ & $3.24 \mathrm{e}-11,1.62 \mathrm{e}-10,3.24 \mathrm{e}-10,1.62 \mathrm{e}-9$, \\
& & $3.24 \mathrm{e}-9,1.62 \mathrm{e}-8$ and $3.24 \mathrm{e}-8$ \\
Reynolds number & $\operatorname{Re}(-)$ & $0.001,0.005,0.01,0.05,0.1,0.5$ and 1.0 \\
Péclet number & $P e(-)$ & $0.64,3.22,6.44,32.20,64.40,322.02$ and \\
& & 644.04 \\
\hline
\end{tabular}

The physical parameters and boundary conditions adopted for simulations are summarized in Table 1. To illustrate the impacts of surface roughness on flow and transport processes under different flow conditions, seven inlet flow conditions with different flowrates were selected in this study, leading to seven Reynolds numbers (Re) and Péclet numbers (Pe) in the fracture model. The Re and Pe are defined as

$$
\begin{aligned}
& R e=\frac{\rho \bar{u} \hat{b}}{W \mu}=\frac{\rho Q}{W \mu} \\
& P e=\frac{\bar{u} \hat{b}}{W D}=\frac{Q}{W D}
\end{aligned}
$$

where $\bar{u}(\mathrm{~m} / \mathrm{s})$ is the mean velocity, $\hat{b}(\mathrm{~m})$ is the characteristic length approximated by the mean fracture aperture, $W(\mathrm{~m})$ is the width of fracture and $Q\left(\mathrm{~m}^{3} / \mathrm{s}\right)$ is the volumetric flowrate. The range of Re and Pe selected for this study commonly exists within the natural or pumping flow conditions.

In solving of NSE and transport equations, the direct solver 'MUMPS' provided in the COMSOL Multiphysics 5.1 was used to solve the system of linear equations. The simulations were conducted in a high-performance workstation, with each solution of steady-state flow and transport for 10 times of the mean residence time taking around 6 hours and demanding around $28 \mathrm{G}$ of physical memory.

\subsection{Flow Field}

The flow velocity field in the Y-direction (the principal flow direction) and streamlines for $R e=0.001$ are exemplified to show the flow behaviors in the 3D rough-walled fracture, presented in Fig. 2.

As shown in Fig. 2a, although the Re number is relatively low $(R e=0.001)$, the velocity values are highly discretely distributed in the fracture space. Low-velocity zones (bluecolored areas) were mostly located around the contact spots, indicating significant impacts of contact spots on flow behaviors that formed multi-rate flow zones in the fracture. The streamlines in Fig. 2b show the flow pass around contact spots and are concentrated in a few 


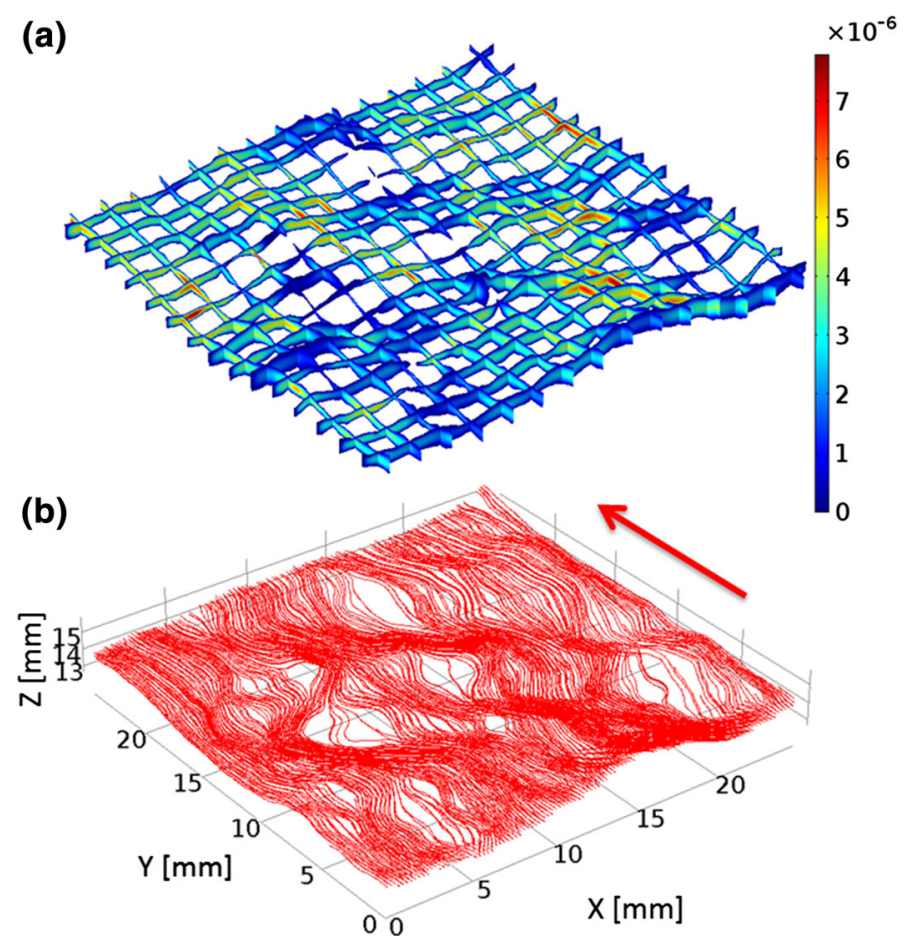

Fig. 2 Flow behavior in the fracture when $R e=0.001$ : a $Y$ component of velocity distribution $\mathbf{b}$ streamlines. Note that in a, the broken parts of the vertical cross-sectional nets showing velocity contour maps are the asperity contact spots, where the velocity contour maps were interrupted. The streamlines shown in b illustrating channel and transverse flows around these corresponding contact spots

channels of higher-velocity zones, indicating strong channelized flow in this rough-walled fracture.

Such non-uniformly and channelized flow behaviors were caused by the complex geometry condition of fracture surface roughness, because it formed variable distribution of apertures, as well as contact spots that directly resulted in a heterogeneous distribution of transmissivity in the fracture.

Figure 3 shows the relationship of effective transmissivity with the local modified apertures. The effective transmissivity $T_{y_{i}}^{e}$ was inversely calculated from the velocity and pressure fields, written as (Zou et al. 2016a)

$$
T_{y_{i}}^{e}=\frac{\rho g \bar{b}_{f}\left(y_{i}\right) \overline{u_{y_{i}}}}{\nabla P_{y} \cos \emptyset_{y_{i}}}
$$

where $\bar{b}_{f}\left(y_{i}\right)$ is the local modified apertures calculated by considering the vertical tortuosity of flow along the mid-surface of the fracture, following Ge (1997) and Nicholl et al. (1999). The $\overline{u_{y_{i}}}$ and $\nabla P_{y}$ are the averaged velocity and pressure gradient across the modified aperture, respectively. The $\emptyset_{y_{i}}$ is the local slope angle of the mid-surface along the $Y$ axis direction.

The theoretical relation between transmissivity and apertures based on the LCL is plotted in Fig. 3 for comparison. The overall trend of blue-colored scatter points (representing effective transmissivity) was generally similar to that of LCL model result (the red curve), showing a stronger correlation between the effective transmissivity and local modified apertures in 


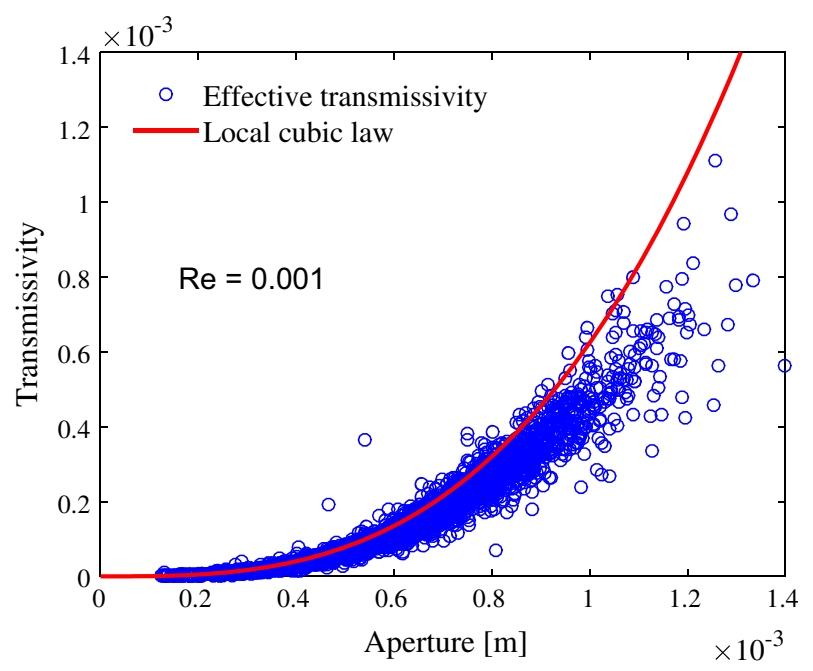

Fig. 3 Relationship between effective transmissivity and aperture

a statistical sense. However, the scatter points still demonstrate important variability with representative average trend below the red curve of the LCL. Such variance in the scatter points also indicates the uncertainty and potential failure of LCL in modeling fluid flow in $3 \mathrm{D}$ rough-walled fractures. The main reason is that the real flow field (as shown in Fig. 2) contains significant channeling and transverse flows in the transverse directions (i.e., $X$ axis and $Z$ axis directions), which is beyond the assumption of LCL that the flow is constrained on same plane of vertical cross sections.

To sum up, the fracture surface roughness significantly increased the complexity of flow behavior and caused important uncertainty in the relationship between velocity, effective transmissivity and apertures. Such impacts on flow will consequently affect the transport in the fracture-matrix system, as will be shown below.

\subsection{Evolution of Concentration Fields}

Figure 4 presents the evolution of the concentration field in the fracture-matrix system model at different times $(0.2,0.6$ and $1.0 \bar{t})$. The cases of $R e=0.001$ and $1.0(P e=0.64$ and 644.04) were exemplified to show the significant differences of concentration distribution features under different flow conditions with low and high flowrates.

In the low flowrate case, when $R e=0.001$, as shown in Fig. 4a, c, e, the concentration field was generally homogenously spreading in the principal flow direction (along $Y$ axis). Only small ranges of variations of concentration along direction of the $X$ axis were shown around the contact spots (Fig. 4c). Also, the concentration field penetrates from the fracture into the matrix, which was shown by gradually change in colors from red to blue along the distance to the fracture, in both up and down directions. It demonstrates the significant effects of matrix diffusion. The main reason for such phenomena is that the transport process is diffusion dominant in low flowrate conditions with low Pe numbers (i.e., $P e=0.4$ ), which covered the impacts of velocity variations caused by the fracture surface roughness.

By contrast, in the high flowrate case when $R e=1.0$, where the transport is dominated by advection $(P e=644.04)$ in the fracture, the concentration field is highly discretely spread along in the fracture (Fig. 4b, d, f). It strongly follows these preferential flow channels and 

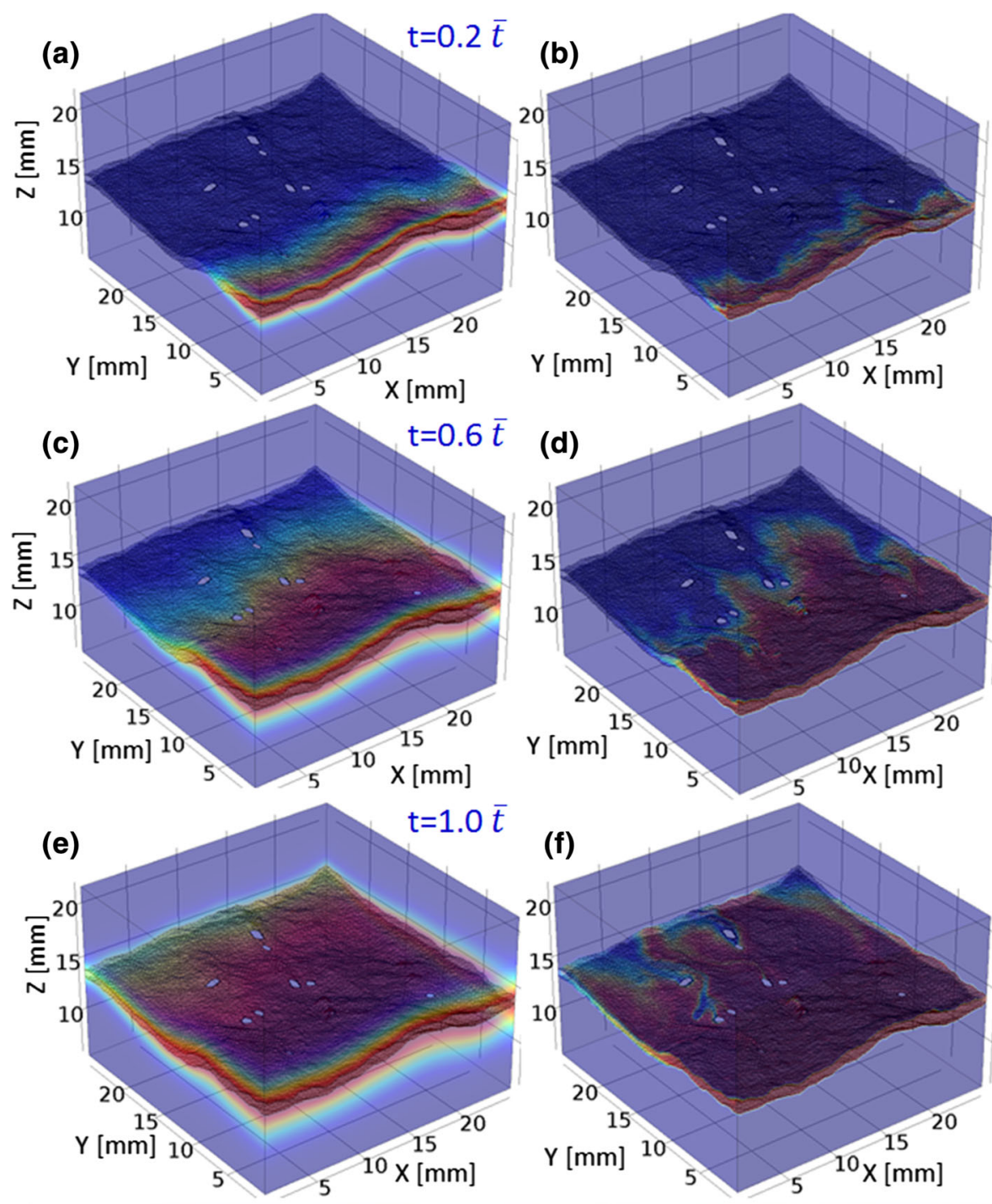

\section{0}

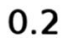

0.4

0.6

0.8

Fig. 4 Propagation of solute transport through fracture-matrix model when $t=0.2 \bar{t}, 0.6 \bar{t}$ and $1.0 \bar{t}: \mathbf{a}, \mathbf{c}, \mathbf{e}$ low flowrate, $R e=0.001$, and $\mathbf{b}, \mathbf{d}, \mathbf{f}$ high flowrate, $R e=1.0$

shows obvious fingering type of transport paths, due to the preferential flow field caused by surface roughness and fracture contacts. Such preferential transport behavior will result in earlier arrival of solute through the high-velocity zone of channels in the fracture space, but heavy tailings of solute spreading in the low-velocity zones around the contact spots. This dispersive transport behavior illustrates that the flow heterogeneity caused by the complex geometry structure of surface roughness has significant impacts on the advection-dominant transport processes in the fracture-matrix system. In addition, due to the relatively shorter 


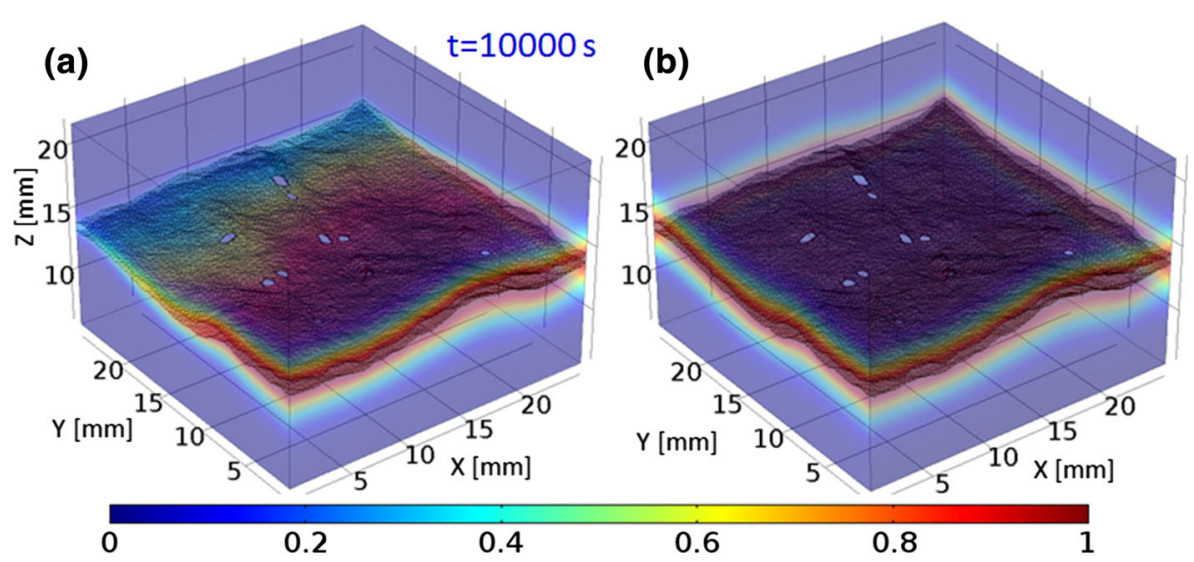

Fig. 5 Concentration field in different flow conditions at the same un-normalized time $t=10,000 \mathrm{~s}$. a $R e=0.001$ and $\mathbf{b} R e=0.01$

time of the mean residence time under high flowrate condition, the matrix diffusion effects become relatively lesser than that in the low flowrate conditions for $R e=0.001$.

In order to show the matrix diffusion effects at the same actual un-normalized time, the concentration field in the fracture-matrix system model when $t=10,000 \mathrm{~s}$ (around $2.78 \mathrm{~h}$ ) for $R e=0.001$ and 0.01 is presented in Fig. 5. At the same actual time, the penetration zones of the concentration in the matrix are relatively larger in the higher flowrate case (i.e., $R e=0.01)$, due to the relatively faster transport in the fracture than that in the low flowrate case (i.e., $R e=0.001$ ). Such different evolution features of concentration field in different flow conditions both at the same normalized and un-normalized time indicate that solute transport in rough-walled fracture-matrix systems is significantly flowrate dependent.

In order to highlight the impacts of contact spots on the concentration distributions, especially in high flowrate case $(R e=1.0)$, the contour maps of concentration at the cross section of $X=12.5 \mathrm{~mm}$ (which contains two contact spots) are presented in Fig. 6. As shown in Fig. 6a, low-concentration zones arise behind the contact spots where the low-velocity zones are. These low-velocity and low-concentration zones play roles as the 'immobile zones' and result in the tailing behavior of transport (Boutt et al. 2006; Cardenas et al. 2007). As time increases, concentration field in these contact spots becomes matrix diffusion process zones as shown in Fig. 6b, with bright red colors at two contact spots. Such phenomenon of contacts with local concentration cannot be found with analytical models and has not been reported in published numerical studies. However, it is a source of uncertainty for both local and overall transport processes when analytical solutions are used. It may have effects on thermal and geochemical processes of the water-rock interactions in the fracture-matrix systems.

\subsection{Breakthrough Curves of the Fracture}

The solute concentration accumulation (breakthrough) features at the outlet boundary of the fracture model, named as cumulative distribution function (CDF), were collected for a more comprehensive and quantitative analysis of the differences between results by analytical solution and numerical simulations in both the spatial and temporal domains. In particular, we wish to show solute concentration tailing distributions in a long term; hence, the complementary cumulative distribution function $(\mathrm{CCDF})$ curves are used to compare results. The CCDF equals to one minus CDF, which emphasizes the tail distribution in the log-plots. 

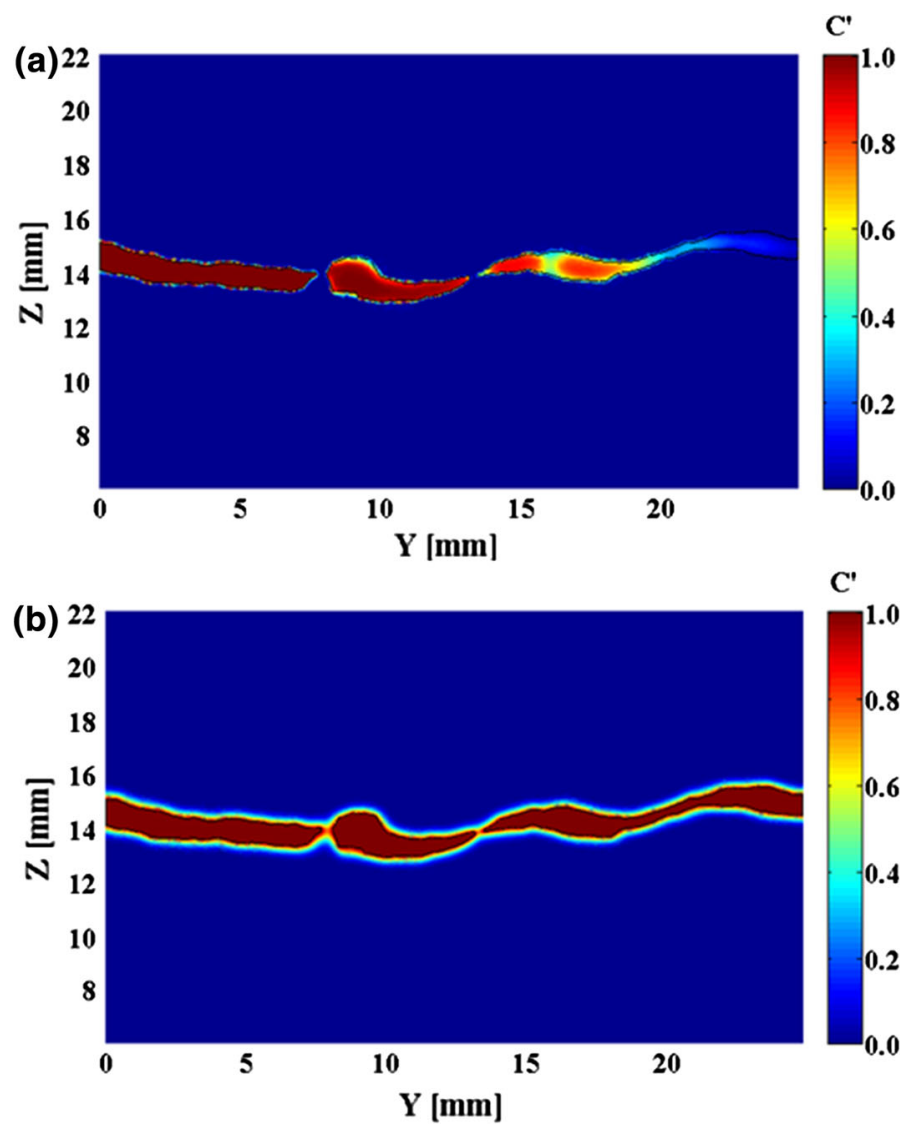

Fig. 6 Concentration evolutions on the cross section of $X=12.5 \mathrm{~mm}$ for $R e=1.0$. a $t=1.0 \bar{t}$ and $\mathbf{b}$ $t=10.0 \bar{t}$

The CCDF curves for the cases $R e=0.001,0.05$ and 1.0 are exemplified in Fig. 7 to show breakthrough features of solute transport in this fracture-matrix system with different flowrates. The results of the analytical solution by Sudicky and Frind (1982) are also plotted for comparison.

Although the CCDF curves by numerical simulation were slightly above the theoretical CCDF curves calculated by the analytical solution, all the simulation results generally converge to the analytical solution asymptotically (i.e., 10 times of their mean residence time), with long tails due to effects of matrix diffusion. This is to be expected since asymptotically, matrix diffusion will be the main factor that controls the solute concentration accumulation. These slight differences were caused by the surface roughness, because of obviously larger areas of the fracture-matrix interfaces in the rough-walled fracture for the matrix diffusion than that in the smoothed parallel plate model used in the analytical solution.

In the short term, i.e., $t<2 \bar{t}$ (within 2 times of their mean residence time), only in the case of $R e=0.001$, the simulation result is generally consistent with the analytical solution. In cases of $R e=0.05$ and 1.0, the simulated CCDF curves show significant differences with the analytical results. Comparing with the analytical solutions, the simulated CCDF curves show much stronger dispersive features with earlier arrivals and heavier tailings. Particularly, such dispersive transport feature is more obvious in the case of high flowrate (i.e., $R e=1.0$ ). 


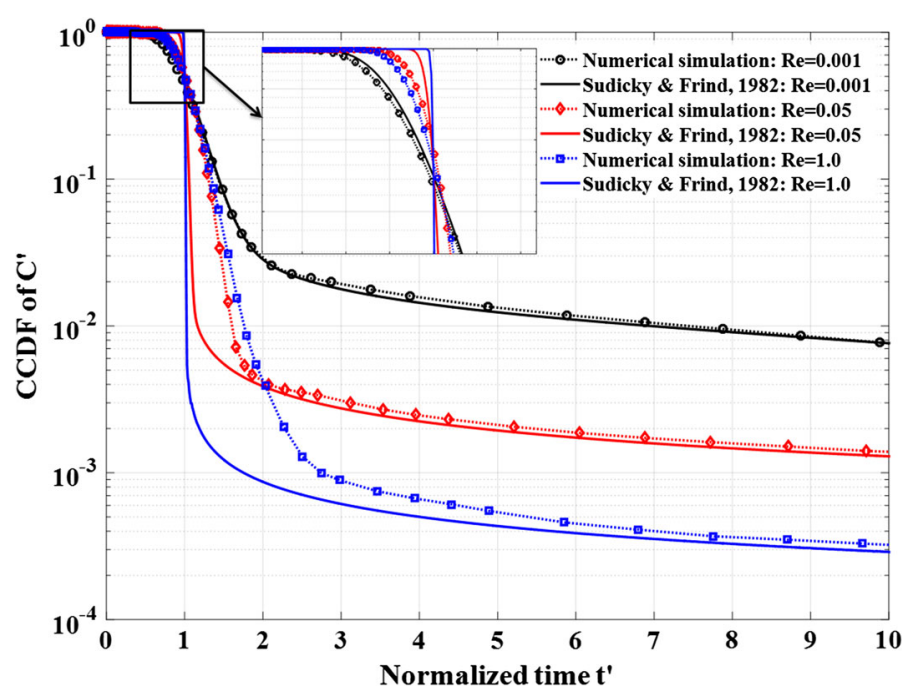

Fig. 7 CCDF curves at the outlet boundary of the fracture of the numerical and analytical models

This finding is consistent with the results of concentration distributions shown in Sect. 4.3, where the flow heterogeneity caused by the fracture surface roughness has much stronger effects on transport process in cases of higher flowrates, due to the increasingly important role of advection with increasing flowrates.

Note that this analytical solution is based on the assumption of full mixing in the fracture. However, in 3D rough-walled fractures, such heterogeneous features in advection-dominant transport processes are beyond this essential assumption, especially in the transverse horizontal direction ( $X$ axis), where the solute is not fully mixed. It is the main reason for the differences between simulation results and analytical solution shown in Fig. 7 for higher Re.

Although the simulated CCDF curves gradually converge to the analytical result, many engineering applications involving mass transports in fractured rocks are of interest on shorter time scales, e.g., of unit mean residence time (Neretnieks 1980; Cvetkovic et al. 1999). Therefore, such significant impact of dispersive transport caused by surface roughness is potentially an important source of uncertainty that should be considered in modeling of solute migration in fractured rocks. It implies that the dispersion coefficient should be accurately quantified in implementation of analytical models.

\subsection{Effective Dispersion Coefficient of the Fracture}

The numerical simulations have shown important dispersive behavior in fracture due to surface roughness, especially when transport is dominated by advection with high flowrates/Re numbers (see Fig. 5). The significant differences in breakthrough curves (see Fig. 7) between numerical simulation results and the analytical solution without considering dispersion have also shown that it is important to consider such dispersion effects in applications (e.g., using Eq. 6).

With the direct simulation of solute transport in this rough-walled fracture-matrix model, its effective dispersion coefficients can be indirectly estimated through curve fitting of simulated results with the analytical solution by using the least square fitting method. However, the formula of analytical solution is nonlinear and contains an integration term. Therefore, the simplest but efficient approach for this one parameter least square fitting is direct searching 


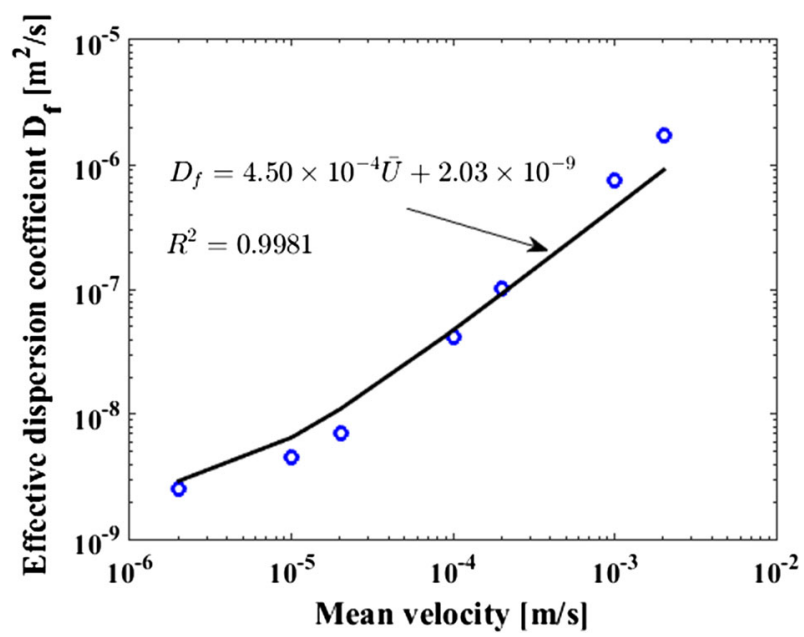

Fig. 8 Effective dispersion coefficients varying with mean flow velocity in the fracture

from a tested range. The searching value of dispersion coefficient leading to the minimum of residues/differences between fitted curves and simulated results was estimated as the effective dispersion coefficient. The obtained effective dispersion coefficients in different cases of Re numbers are plotted against mean velocities, shown in Fig. 8.

The effective dispersion coefficients (blue dots) show an approximately linear relation with mean flow velocities, which agrees well with the linear fitting by Eq. 6, with square of correlation coefficient $R^{2}$ lager than 0.99 . According to the physical meaning of Eq. 6, the coefficient of $4.5 \times 10^{-4} \mathrm{~m}$ was estimated as the longitudinal dispersivity for this fracture model.

The issue of how to accurately estimate dispersion coefficients or the longitudinal dispersivity in natural rock fractures is still open. In most applications, the dispersion coefficient, especially the longitudinal dispersivity, was adopted empirically, due to the difficulties and uncertainties in field tracer tests and laboratory experiments (e.g., Tang et al. 1981). In addition, many investigations have shown that dispersivity in natural fractures is closely related to specific flow (flowrates) and geometry (surface roughness and scales) conditions (Pickens and Grisak 1981; Zhou et al. 2007; Zhao et al. 2010). Therefore, to obtain more general and accurate estimates of the dispersion coefficient and dispersivity, a large number of statistical and multi-scale analyses are required.

\subsection{Concentration Profiles in the Matrix}

As shown above in the concentration fields (Fig. 5) and CCDF curves (Fig. 7), the matrix diffusion plays a significant role in the solute transport process. The contour map of concentration on a vertical cross section at $Y=12.4 \mathrm{~mm}$ of the fracture-matrix system model is plotted in Fig. 9, to show the concentration distribution feature. To further quantitatively compare simulated results with the analytical solution (the red curve), a set of concentration profiles (blue curves) along the vertical distance from the upper fracture surface on this cross section are also presented in Fig. 9. These profiles were interpolated from simulation results on 63 lines along the vertical distance from the upper fracture surface. The locations or interval of these lines are chosen according to the topographical interval of the surface roughness $\left(I_{X}=I_{Y}=0.4 \mathrm{~mm}\right)$. Note that due to the single process of diffusion in the matrix, 


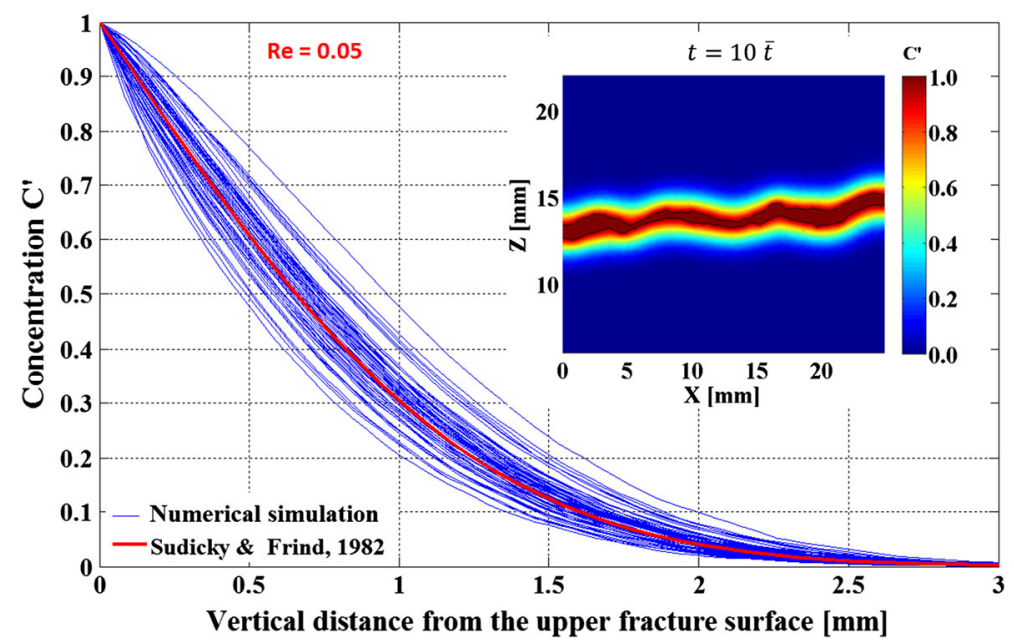

Fig. 9 Contour map and concentration profiles on a vertical cross section at $Y=12.4 \mathrm{~mm}, R e=0.05$

the concentration distribution in the matrix is dependent on the time scale. For simplicity, only the case of $R e=0.05$ (with the modulate flowrate simulated in this study) for $t=10 \bar{t}$ is exemplified in this section, for a general illustration and quantitative comparison.

The contour map shows clear diffusion/penetration zones starting from the fracture surface into the matrix gradually. The concentration in the fracture is close to 1.0 due to relatively long-term $(t=10 \bar{t}$ ) advection (Fig. 9). The concentration distribution in the matrix along the fracture generally follows the patterns of surface roughness, but with much smoother iso-surface of diffusion/penetration zones than the structure of surface roughness. This result reflects the nature of diffusion that eventually leads to a homogenous distribution of concentration in the entire domain when an adequate time scale is reached.

The simulated results of concentration profiles (blue curves) for the matrix show a strong spatial variability around the theoretical solution (the red curve) (see Fig. 9). The good agreement between the theoretical solution and the average of concentration profiles demonstrates that the analytical solution is robust in general trend, but limited for evaluating uncertain variations in the real rough-walled fracture-matrix systems.

The main reason for the variations of concentration profiles in the matrix is the flow heterogeneity in the fracture caused by surface roughness, which yields the non-uniformly distributed concentration on the interfaces that acts as the boundary condition for matrix diffusion. It is demonstrated in the contour maps of concentration distribution on the cross section at an early stage of transport (i.e., $t=0.6 \bar{t}$ ), shown in Fig. 10.

As shown in Fig. 10, in both cases of $R e=0.001$ and 0.05 , at the earlier stage of transport, the concentration is non-uniformly distributed in the fracture, as well as on the interfaces, due to variant flow and advection velocities in the fracture. Such non-uniformly boundary condition for the matrix diffusion will consequently result in variations of concentration profiles in the matrix.

\subsection{Importance of Transverse Diffusion in the Matrix}

Another significant reason for the variations of concentration profiles is caused by the transverse diffusion in the matrix. Comparing with the analytic solution, the numerical model 


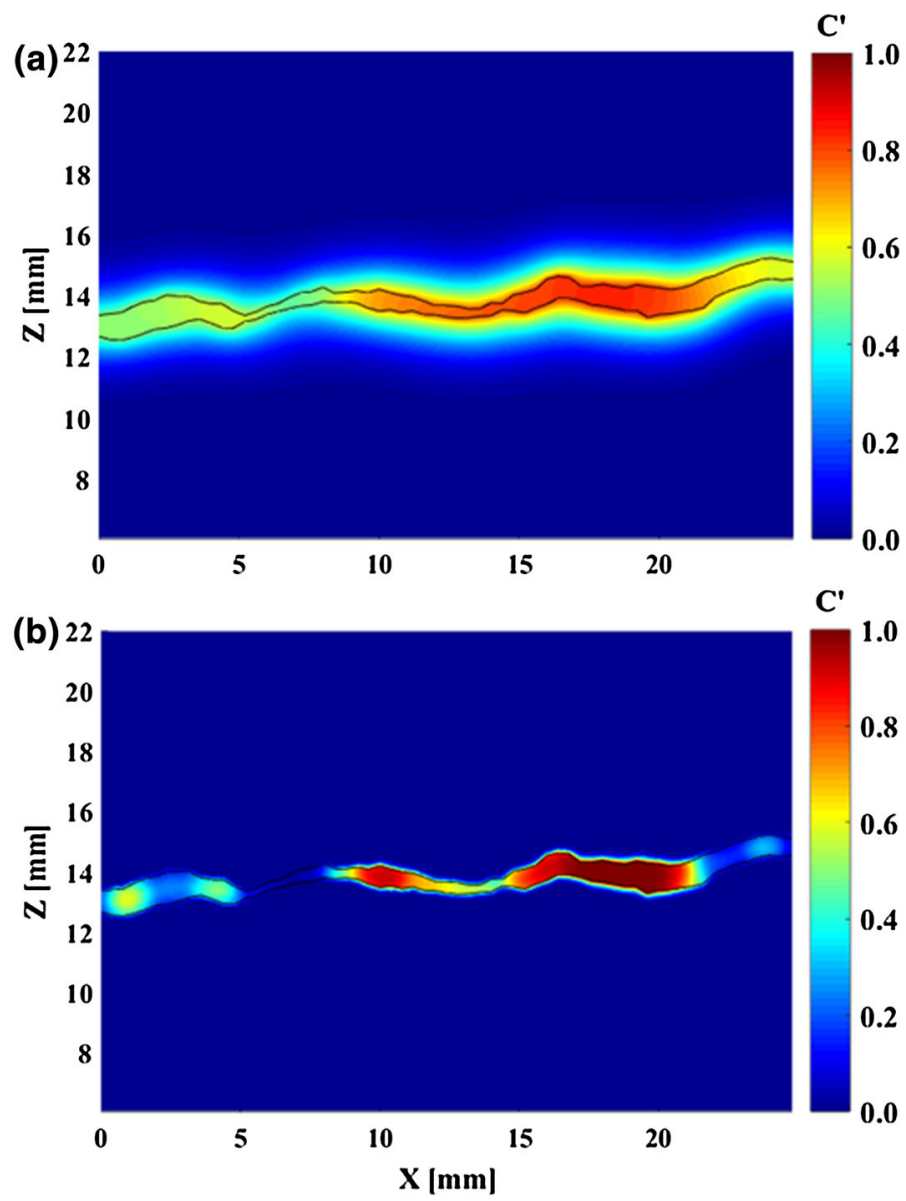

Fig. 10 Concentration distribution on cross section $Y=12.4 \mathrm{~mm}$, when $t=0.6 \bar{t}$. a $\operatorname{Re}=0.001$ and $\mathbf{b}$ $R e=0.05$

realistically simulated full 3D diffusion in the matrix, which cannot be conducted by the analytical solution because the matrix diffusion in the transverse directions (i.e., directions parallel to the fracture surface) was ignored. This issue was discussed in Zou et al. (2016b) in the context of a 2D smooth parallel plate fracture-matrix model. It was found that transverse diffusion can have a significant impact on the solute concentration distributions in the rock matrix. Considering the $3 \mathrm{D}$ rough-walled fractures, the effects of transverse diffusion in the matrix become a more important factor that causes significant variations and uncertainties in concentration distribution in the matrix, as shown in Fig. 9.

To illustrate the importance of transverse diffusion in the rock matrix, simulation results of a test case with $R e=0.05$ are shown in Fig. 11. In this case, the transverse matrix diffusion was switched off by setting the effective diffusion coefficients in the $X$ and $Y$ directions as 0 . The contour map and concentration profiles for the same cross section at $Y=12.4 \mathrm{~mm}$ are presented in Fig. 11, for comparison.

The contour map in Fig. 11 obviously shows rougher iso-surface/line of concentration distribution, which is directly related to the local surface roughness. Meanwhile, the matrix 


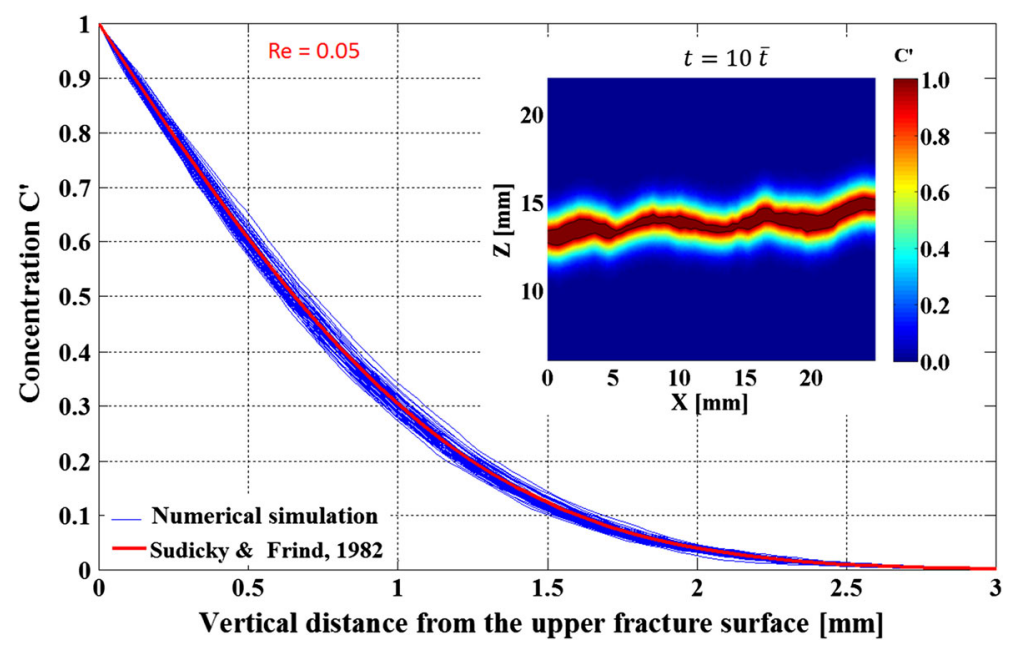

Fig. 11 Concentration profiles for the cross section at $Y=12.4 \mathrm{~mm}, R e=0.05$, without considering transverse diffusion in the rock matrix

concentration profiles (blue curves) along the vertical distance from the upper fracture face show much less variation with respect to the analytical solution (the red curve) than the real case where the full 3D matrix diffusion is considered (see Fig. 9). In order to quantitatively compare derivations of concentration profiles with the analytical result, the root-mean-square derivation (RMSD) was calculated and presented in the boxplot shown in Fig. 12. The RMSD is expressed as

$$
\operatorname{RMSD}=\sqrt{\frac{1}{n} \sum_{i=1}^{n}\left(C_{i}^{s}-C_{i}^{a}\right)^{2}}
$$

where $C_{\mathrm{i}}^{\mathrm{s}}$ and $C_{\mathrm{i}}^{\mathrm{a}}$ are the solute concentration at the $i$ th point to be compared, as the numerical and analytical results, respectively. Integer $n$ is the number of comparing points.

The boxplots of RMSD in Fig. 12 show that once the transverse matrix diffusion is ignored, the concentration profiles are more close to the analytical solution, with significantly reduced mean, deviation range and extreme values of the RMSD. This result verifies that transverse matrix diffusion can be the reason for variations of the concentration distribution in the matrix shown in Fig. 9. It may therefore be necessary in applications with more complex processes between solute and matrix (such as sorption, precipitation and dissolution processes) to include these variations for accurate quantification, depending once again on the objective of the modeling.

\section{Discussion}

\subsection{Comparison with Simplified Numerical Models Based on the Reynolds Equation}

In addition to analytical models, the Reynolds equation is also widely applied in modeling of flow and transport in rock fractures, due to its simplicity and ability to account for surface 


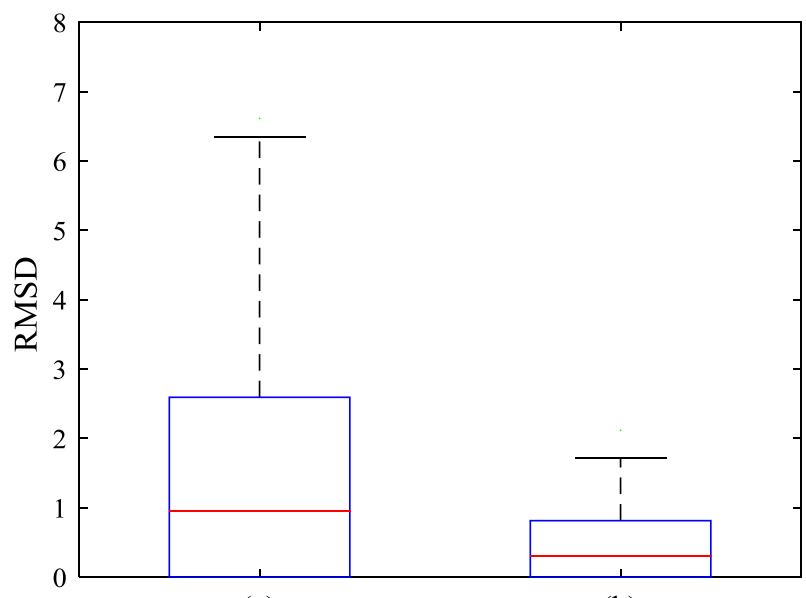

(a)

(b)

Fig. 12 Boxplots of the differences (represented by the root-mean-square derivation) in concentration profiles between numerical simulation and the analytical solution: a with and $\mathbf{b}$ without consideration of the transverse diffusion in numerical simulation

roughness effects by using LCL. The results of flow and advection-dominated transport by comparison of NSE and Reynolds equations were presented, in order to further quantify the uncertainties in modeling of flow by Reynolds equation. The Reynolds equation is written as

$$
\frac{\partial}{\partial x}\left(\frac{b^{3}}{12 \mu}\right) \frac{\partial P}{\partial x}+\frac{\partial}{\partial y}\left(\frac{b^{3}}{12 \mu}\right) \frac{\partial P}{\partial y}=0
$$

A finite element method (FEM) code was developed to obtain numerical solutions of the Reynolds equation, for the comparison with NSE results in this study.

Figure 13 presents spatial distribution of relative differences between the velocity field calculated by solving NSE and Reynolds equation, for $R e=0.001$. The relative differences of local velocity $\xi_{U}$ are defined as

$$
\xi_{U}=\frac{U_{N S E}-U_{R E}}{U_{N S E}} \times 100 \%
$$

where $U_{N S E}$ and $U_{R E}$ are the normal velocity solved by NSE and Reynolds equation, respectively. Note that $U_{N S E}$ is linearly interpolated from the 3D velocity fields by solving NSE, because of different meshes used in solving NSE and Reynolds equation (i.e., 3D mesh for NSE but 2D mesh for the Reynolds equation).

The comparison of local velocity shows significant relative differences between results of NSE and Reynolds equations. The value of $\xi_{U}$ ranges from -215 to $60 \%$. Particularly, the areas near the shear induced contacts show relatively higher differences.

In order to compare transport in consideration of matrix diffusion based on the Reynolds equation, a particle tracking technique was used to simulate the transport in the fracturematrix system, following researches by Yamashita and Kimura (1990) and Moreno and Neretnieks (1993). Note that the dispersion in the fracture is ignored in this transport model. The travel time for each particle in the fracture is determined by using uniform random number in the interval $[0,1]$. The travel time $t$ is calculated from 


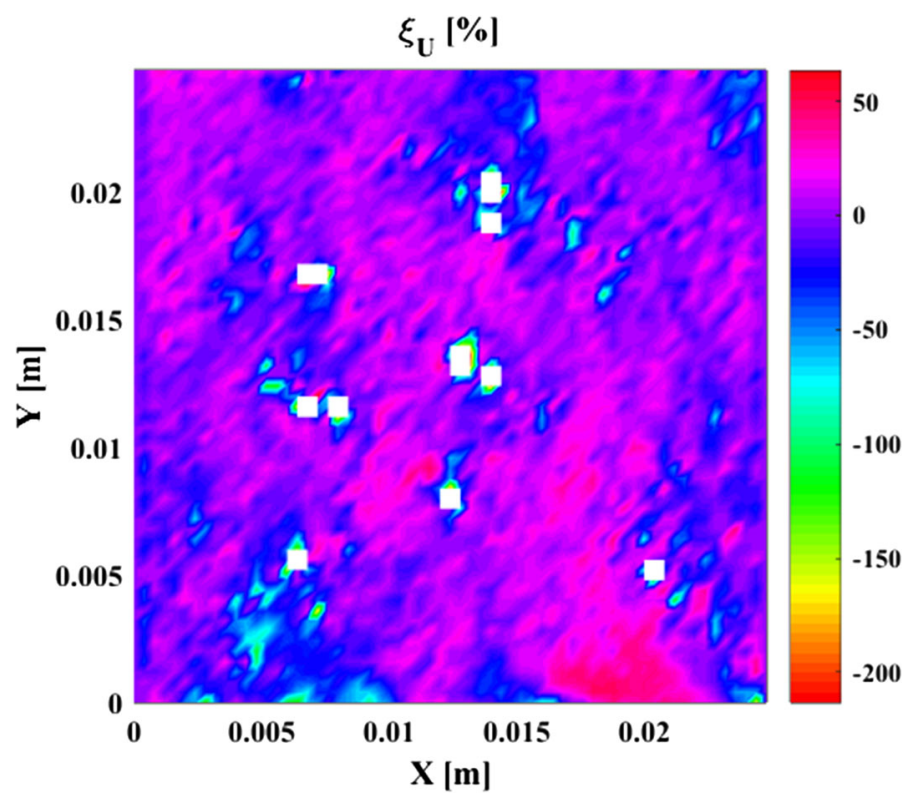

Fig. 13 Differences of local velocity between NSE and Reynolds equations, $R e=0.001$. The white voids represent the shear caused contacts

$$
[R]_{0}^{1}=\operatorname{erfc}\left[\frac{\theta D_{m}^{1 / 2}}{b} \frac{t_{w}}{\left(t-t_{w}\right)^{1 / 2}}\right]
$$

where $[R]_{0}^{1}$ is a random number between 0 and 1 from uniform distribution and $t_{w}(\mathrm{~s})$ is the travel time due to advection calculated from particle tracking.

Figure 14 shows the comparison of CCDF curves calculated by direct simulation based on NSE and by the particle tracking based on the Reynolds equation. When Re is relatively small (i.e., $R e=0.001$ ), the CCDF curves calculated by the particle tracking based on the Reynolds equation show larger differences from those by direct simulation based on NSE, due to ignoring dispersion in the fracture through particle tracking method. When Re increases, the CCDF curves calculated by the two models approach with each other in long-term transport. Comparing with the analytical solution by Sudicky and Frind (1982) shown in Fig. 7, the results by the particle tracking based on the Reynolds equation are more consistent with those by direct simulation based on NSE, because the heterogeneous flow caused by the surface roughness can be captured by the Reynolds equation. However, due to ignoring dispersion in the fracture, the results by the particle tracking based on the Reynolds equation may still contain important uncertainty, especially the transverse dispersion. Unlike more realistic velocity field provided by solving the NSE in 3D, the velocity calculated by the Reynolds equation is a $2 \mathrm{D}$ averaged velocity across the aperture of the same fracture geometry model.

\subsection{Effects of Shear}

It is known that shear significantly affects the fracture flow by changing the aperture structures and creating asperity contacts between the two rough surfaces of the fracture, as described in 


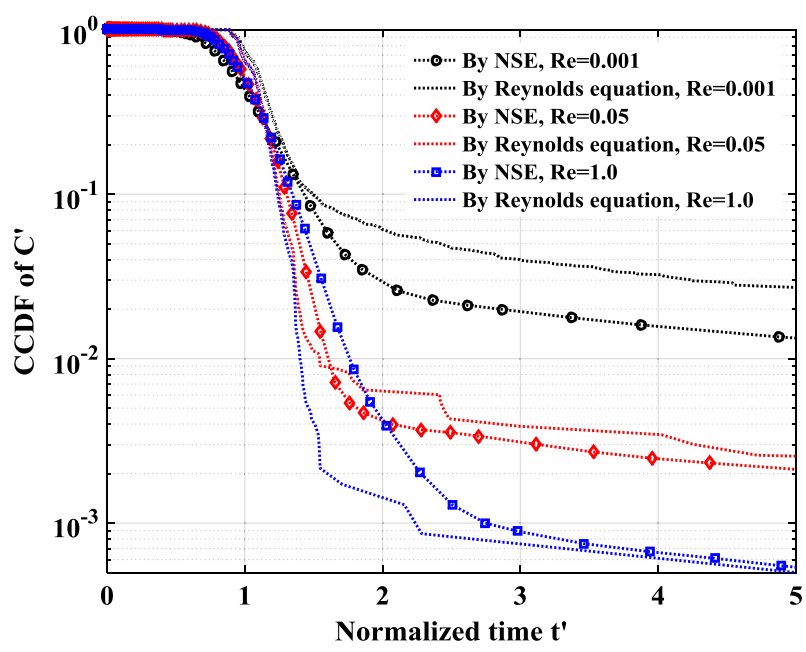

Fig. 14 Comparison of CCDF curves calculated by direct simulation based on NSE and by the particle tracking based on the Reynolds equation

previous sections. In order to highlight the shear effects, another set of simulation with the same initial and boundary conditions, but using the un-sheared fracture model was conducted for comparison. In this un-sheared fracture model, the aperture is constant (equals to $0.65 \mathrm{~mm}$ ) which is the same as the mean aperture of the sheared model (see Fig. 1).

Figure 15a shows the concentration distribution when $R e=1.0(P e=644.04)$ and $t=0.6 \bar{t}$ in the un-sheared fracture model. Comparing with result in the sheared model (see Fig. 4d), the concentration field is more homogeneous, despite that there are still preferential advections due to the surface roughness and tortuous flows.

Figure $15 \mathrm{~b}$ presents the CCDF curves in the un-sheared fracture model when $R e=0.001$, 0.05 and 1.0 as well as the analytical results for comparison. Comparing with that in the sheared model (see Fig. 7), the CCDF curves are more close to the analytical results. The effective dispersivity of this un-sheared fracture model is $1.62 \times 10^{-4} \mathrm{~m}$. It is much smaller than that in the sheared fracture model.

In previous studies by direct simulation of flow and transport in 3D rock fractures, the shear effects, especially that of the asperity contacts, were rarely considered. However, above comparison proved that the shear significantly enhanced the dispersive behaviors of solute transport process in rock fractures under mechanical loading conditions. The main reason is that the shear process causes much aperture structure changes, and asperity contacts consequently enhance the flow heterogeneity with significant transverse flows. In applications, such impacts of shear on solute transport therefore should be properly considered.

\subsection{More Complicated Flow Conditions Affecting 3D Effects}

In order to compare with the analytical model, we only simulated the most common case of one principal direction flow (in the $Y$ axis direction). However, such idealized flow condition is a much simplified flow type in real 3D rock fractures and fracture networks, where the fracture flow may occur in any combination of inflow and outflow conditions, depending on the hydrogeological and mechanical conditions in nature (i.e., hydraulic gradient and geometric connections). To illustrate the flow and transport behaviors in more complicated 
(a)
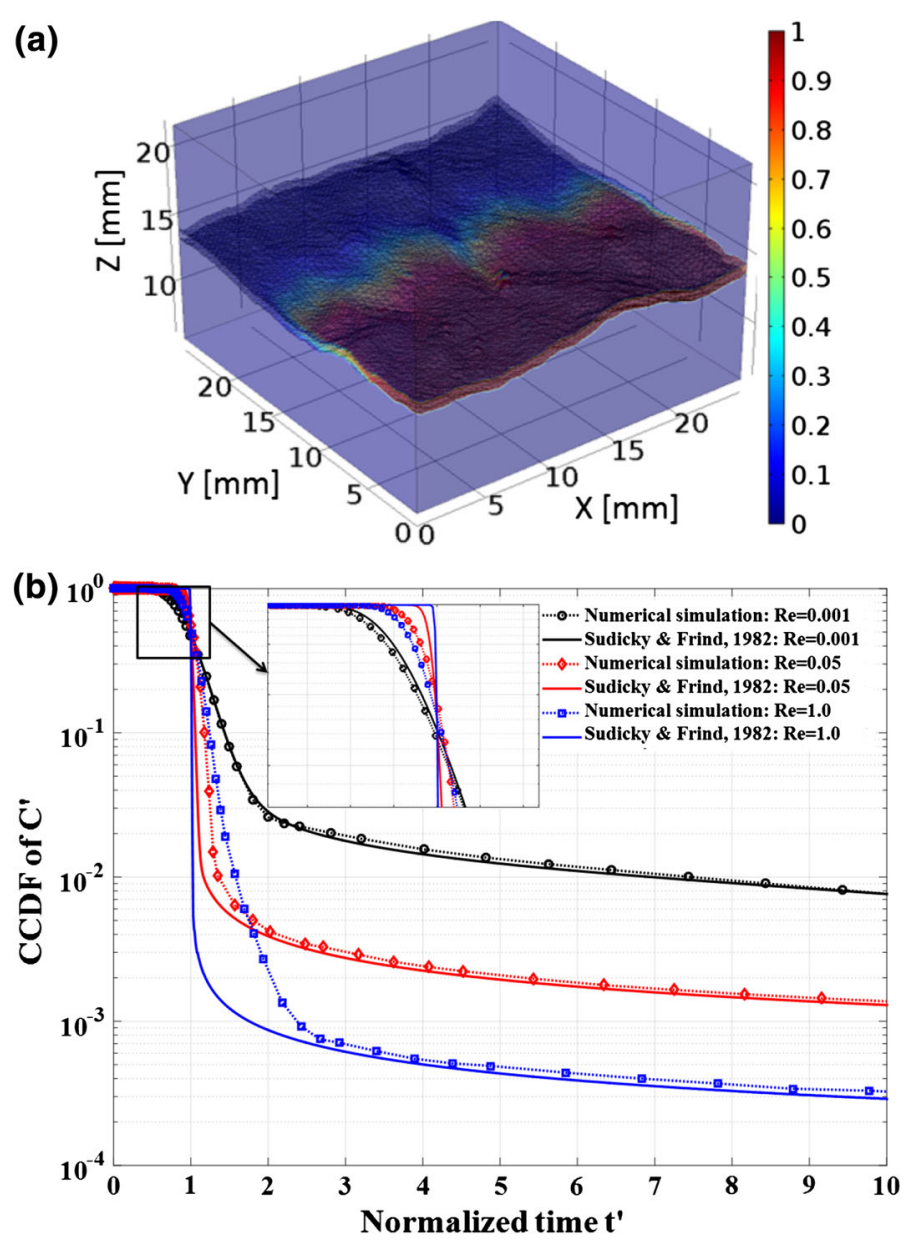

Fig. 15 a Concentration distribution when $R e=1.0$ and $\mathbf{b}$ CCDF curves in the un-sheared fracture model

flow conditions, three other typical flow cases with inflow $Q=3.2423 \times 10^{-8} \mathrm{~m}^{3} / \mathrm{s}$ were simulated and presented in Fig. 16, with different specifications of inlet and outlet boundary conditions.

Figure 16a, c and e shows the streamlines of these three flow types, illustrating the more complicated channeling flow paths in the 3D fracture. Figure $16 \mathrm{~b}, \mathrm{~d}, \mathrm{f}$ presents the breakthrough curves on the outlets of these models. The complicated channeling flows in fractured rocks have been extensively investigated at field scales in previous studies (e.g., Nordqvist et al. 1992; Tsang and Neretnieks 1998). Above results of streamlines and breakthrough curves generally illustrate the complicated channeling flows and multi-rate transport behaviors (due to the preferential channeling advection) at the scale of single fractures. The original reason for these phenomena is still the complex surface roughness which caused the heterogeneity of transmissivity. This finding shows that the flow boundary condition is an important factor for design laboratory experiments on fracture flow and transport, since most of tests with only forced one principal flow direction may cause unknown estimation of the flow and transport properties of the rough-walled rock fractures. 

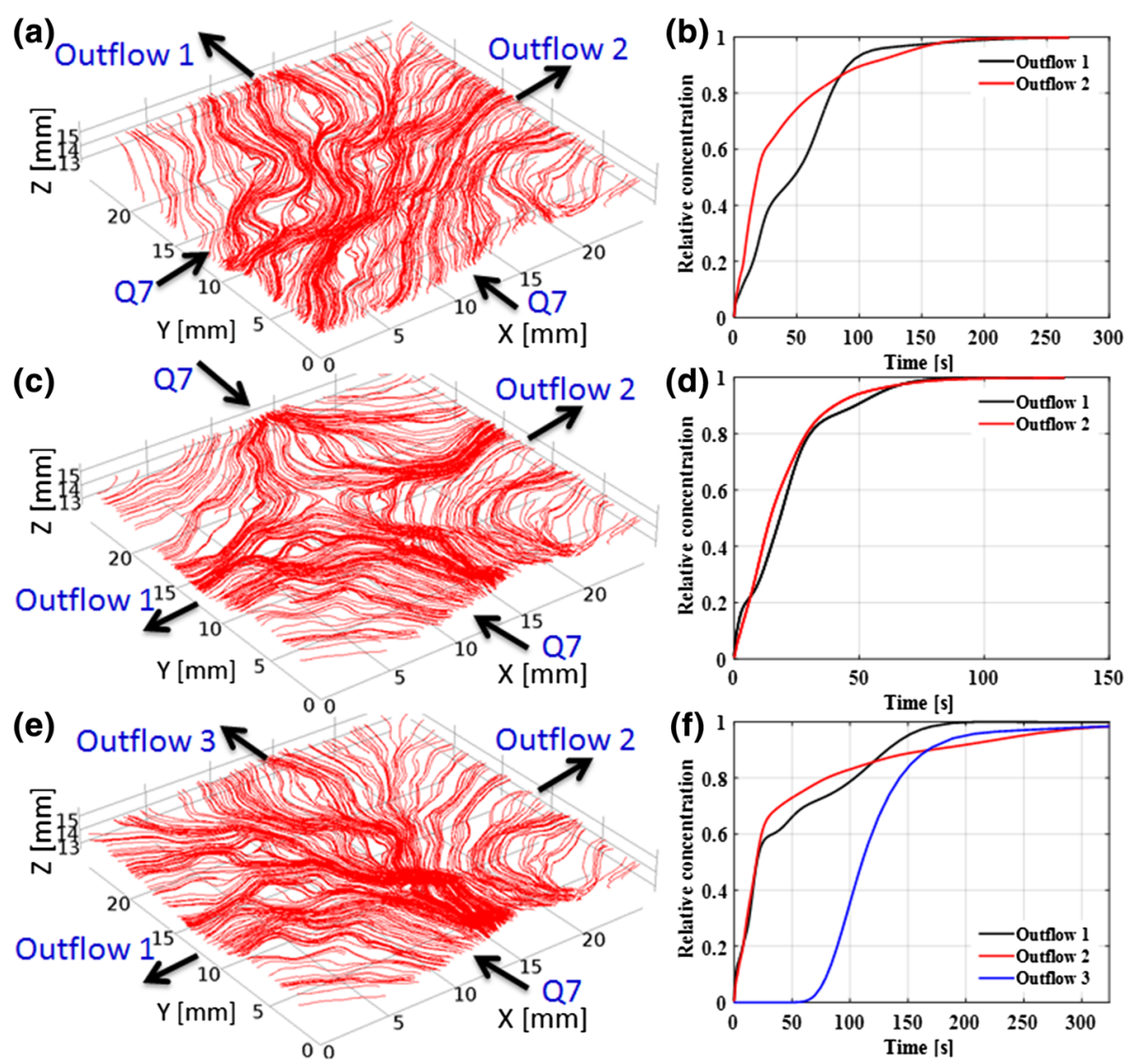

Fig. 16 Streamline and breakthrough curve of different flow conditions

\section{Conclusion}

Some general conclusions from this study are summarized as follows:

- The complex geometry of fracture surface roughness, as well as fracture contacts/closures, significantly increases the complexity and heterogeneity of flow fields in $3 \mathrm{D}$ rough-walled fractures, even when $\mathrm{Re}$ is small (i.e., $R e=0.001$ ). The variations in the effective transmissivity demonstrate important uncertainty in modeling of flow by using the LCL model. Particularly, in the comparison of the flow field, the relative differences between results based on NSE and the Reynolds equation (using the LCL model) range significantly from -215 to $60 \%$ in this study.

- The surface roughness causes flow heterogeneity and consequently affects transport behavior in the fracture-matrix systems. It causes dispersion (solute spread following the preferential flow channels) of concentration in the fracture. Such dispersive transport behavior becomes increasingly important with increases in Re and Pe numbers, due to the increasingly stronger advection effects.

- The flow and transport model by the particle tracking based on the Reynolds equation can capture the heterogeneous flow caused by the surface roughness. However, its results 
may still contain important uncertainty due to potential errors in the much simplified flow field and the ignoring of dispersion.

- The fracture surface roughness also leads to important variations/uncertainties of concentration profiles in the matrix, due to both flow heterogeneity in the fracture and transverse diffusion in the matrix, which are neglected in the analytical solutions. Such variations may bring more uncertainties when the local concentration related processes (e.g., precipitation/dissolution) need to be considered.

- In 3D rough-walled fracture-matrix systems, the non-fully mixed condition in the fracture and transverse diffusion in the matrix may become important sources of uncertainties in applications, which cannot be considered in the analytical solutions.

- Direct 3D simulations by solving NSE and transport equations are useful as numerical experiments, which help us to test applicability of analytical solutions, to determine the effective dispersion coefficient and to better understand potential uncertainties in applications of analytical models for natural fracture flow and transport problems.

This study considers only the two major transport mechanisms of advection and dispersion/diffusion in the fracture and matrix diffusion in the matrix, for highlighting the impacts of surface roughness of rock fractures. As the critical interface between the fracture and matrix, the rough-walled surfaces will also affect other transport mechanisms, such as surface sorption and chemical reactions, due to the increased specific surface areas (Neretnieks 1980; Wels et al. 1996; Cvetkovic et al. 1999). To obtain more comprehensive understanding of transport behavior in natural fractured rocks when a broader range of processes is active, further studies are needed.

Acknowledgements The first author would like to thank the financial support of China Scholarship Council (CSC) (Grant Number 201208420602) and the National Natural Science Foundation of China (NSFC) (Grant Number 41372359). VC would like to acknowledge the support by the Swedish Nuclear Fuel and Waste Management Co. (SKB). We thank the three anonymous reviewers for their constructive comments to improve this manuscript.

Open Access This article is distributed under the terms of the Creative Commons Attribution 4.0 International License (http://creativecommons.org/licenses/by/4.0/), which permits unrestricted use, distribution, and reproduction in any medium, provided you give appropriate credit to the original author(s) and the source, provide a link to the Creative Commons license, and indicate if changes were made.

\section{References}

Abdel-Salam, A., Chrysikopoulos, C.V.: Analytical solutions for one-dimensional colloid transport in saturated fractures. Adv. Water Resour. 17, 283-296 (1994)

Abdel-Salam, A., Chrysikopoulos, C.V.: Modeling of colloid and colloid-facilitated contaminant transport in a two-dimensional fracture with spatially variable aperture. Transp. Porous Med. 20, 197 (1995). doi:10. 1007/BF01073172

Bodin, J., Delay, F., de Marsily, G.: Solute transport in fissured aquifers: 1. Fundamental mechanisms. Hydrogeol. J. 11, 418-433 (2003a)

Bodin, J., Delay, F., de Marsily, G.: Solute transport in a single fracture with negligible matrix permeability: 2. Mathematical formalism. Hydrogeol. J. 11, 434-454 (2003b)

Boutt, D.F., Grasselli, G., Fredrich, J.T., Cook, B.K., Williams, J.R.: Trapping zones: the effect of fracture roughness on the directional anisotropy of fluid flow and colloid transport in a single fracture. Geophys. Res. Lett. 2006(33), L21402 (2006)

Cardenas, M.B., Slottke, D.T., Ketcham, R.A., Sharp, J.M.: Navier-Stokes flow and transport simulations using real fractures shows heavy tailing due to eddies. Geophys. Res. Lett. 2007(34), L14404 (2007) 
Chrysikopoulos, C.V., James, S.C.: Transport of neutrally buoyant and dense variably sized colloids in a twodimensional fracture with anisotropic aperture. Transp. Porous Media 51, 191 (2003). doi:10.1023/A: 1021952226861

Crandall, D., Bromhal, G., Karpyn, Z.T.: Numerical simulations examining the relationship between wallroughness and fluid flow in rock fractures. Int. J. Rock Mech. Min. Sci. 47, 784-796 (2010)

COMSOL (2016) http://www.comsol.com/

Cvetkovic, V., Selroos, J.O., Cheng, H.: Transport of reactive tracers in rock fractures. J. Fluid Mech. 378, 335-356 (1999)

Esposito, S.J., Thomson, N.R.: Two-phase flow and transport in a single fracture-porous medium system. J. Contam. Hydrol. 37(3-4), 319-341 (1999)

Ge, S.: A governing equation for fluid flow in rough fractures. Water Resour. Res. 33(1), 53-61 (1997). doi:10. 1029/96WR02588

Grisak, G.E., Pickens, J.F.: Solute transport through fractured media: 1. The effect of matrix diffusion. Water Resour. Res. 16(4), 719-730 (1980). doi:10.1029/WR016i004p00719

Kennedy, C.A., Lennox, W.C.: A control volume model of solute transport in a single fracture. Water Resour. Res. 31(2), 313-322 (1995). doi:10.1029/94WR01967

Koyama, T., Neretnieks, I., Jing, L.: A numerical study on differences in using Navier-Stokes and Reynolds equations for modeling the fluid flow and particle transport in single rock fractures with shear. Int. J. Rock Mech. Min. Sci 45(7), 1082-1101 (2008)

Kumar, G.S.: Effect of sorption intensities on dispersivity and macro-dispersion coefficient in a single fracture with matrix diffusion. Hydrogeol. J. 16(2), 235-249 (2008)

Lee, S.H., Lee, K.K., Yeo, I.W.: Assessment of the validity of Stokes and Reynolds equations for fluid flow through a rough-walled fracture with flow imaging. Geophys. Res. Lett 41(13), 4578-4585 (2014)

Lee, S.H., Yeo, I.W., Lee, K.K., Detwiler, R.L.: Tail shortening with developing eddies in a rough-walled rock fracture. Geophys. Res. Lett. 42, 6340-6347 (2015). doi:10.1002/2015GL065116

Liu, H.H., Mukhopadhyay, S., Spycher, N., Kennedy, B.M.: Analytical solutions of tracer transport in fractured rock associated with precipitation-dissolution reactions. Hydrogeol. J. 19, 1151-1160 (2011)

Moreno, L., Tsang, Y.W., Tsang, C.F., Hale, F.V., Neretnieks, I.: Flow and tracer transport in a single fracture: a stochastic model and its relation to some field observations. Water Resour. Res. 24, 2033-2048 (1988)

Moreno, L., Neretnieks, I.: Flow and nuclide transport in fractured media: the importance of the flow-wetted surface for radionuclide migration. J. Contam. Hydrol. 13(1993), 49-71 (1993)

Neretnieks, I.: Diffusion in the rock matrix: an important factor in radionuclide retardation? J. Geophys. Res. 85(B8), 4379-4397 (1980). doi:10.1029/JB085iB08p04379

Neretnieks, I.: Stress-mediated closing of fractures: impact of matrix diffusion. J. Geophys. Res. Solid Earth. 119, 4149-4163 (2014). doi:10.1002/2013JB010645

Nicholl, M.J., Rajaram, H., Glass, R.J., Detwiler, R.: Saturated flow in a single fracture: evaluation of the Reynolds equation in measured aperture fields. Water Resour. Res. 35(11), 3361-3373 (1999). doi:10. 1029/1999WR900241

Nordqvist, A.W., Tsang, Y.W., Tsang, C.F., Dverstorp, B., Andersson, J.: A variable aperture fracture network model for flow and transport in fractured rocks. Water Resour. Res. 28(6), 1703-1713 (1992)

Pickens, J.F., Grisak, G.E.: Modelling of scale-dependent dispersion in hydrogeological systems. Water Resour. Res. 17(6), 1701-1711 (1981)

Renu, V., Kumar, G.S.: Numerical modeling and spatial moment analysis of solute mobility and spreading in a coupled fracture-skin-matrix system. Geotech. Geol. Eng. 30, 1289-1302 (2012). doi:10.1007/s10706012-9540-3

Roubinet, D., de Dreuzy, J.-R., Tartakovsky, D.M.: Semi-analytical solutions for solute transport and exchange in fractured porous media. Water Resour. Res. 48, W01542 (2012). doi:10.1029/2011WR011168

Sudicky, E.A., Frind, E.O.: Contaminant transport in fractured porous media: analytical solutions for a system of parallel fractures. Water Resour. Res. 18(6), 1634-1642 (1982)

Tang, D.H., Frind, E.O., Sudicky, E.A.: Contaminant transport in fractured porous media: analytical solution for a single fracture. Water Resour. Res. 17(3), 555-564 (1981)

Tsang, C.-F., Neretnieks, I.: Flow channeling in heterogeneous fractured rocks. Rev. Geophys. 36(2), 275-298 (1998). doi:10.1029/97RG03319

Thompson, M.E., Brown, S.R.: The effect of anisotropic surface roughness on flow and transport in fractures. J. Geophys. Res. 96(B13), 21923-21932 (1991). doi:10.1029/91JB02252

Wang, L., Cardenas, M.B.: Non-Fickian transport through two-dimensional rough fractures: assessment and prediction. Water Res. Res. 50(2), 871-884 (2014). doi:10.1002/2013wr014459

Wang, L., Cardenas, M.B., Slottke, D.T., Ketcham, R.A., Sharp Jr., J.M.: Modification of the Local Cubic Law of fracture flow for weak inertia, tortuosity and roughness. Water Resour. Res. 51, 2064-2080 (2015) 
Wels, C., Smith, L., Vandergraaf, T.T.: Influence of specific surface area on transport of sorbing solutes in fractures: an experimental analysis. Water Res. Res. 32(7), 1943-1954 (1996)

Xiong, X., Li, B., Jiang, Y., Koyama, T., Zhang, C.: Experimental and numerical study of the geometrical and hydraulic characteristics of a single rock fracture during shear. Int. J. Rock Mech. Min. Sci. 48(8), 1292-1302 (2011)

Yamashita, R., Kimura, H.: Particle-tracking technique for nuclide decay chain transport in fractured porous media. J. Nucl. Sci. Technol. 27, 1041-1049 (1990)

Yeo, I.W.: Effect of fracture roughness on solute transport. Geosci. J. 5(2), 145-151 (2001)

Zhan, H., Wen, Z., Huang, G., Sun, D.: Analytical solution of two-dimensional solute transport in an aquiferaquitard system. J. Contam. Hydrol. 107(3-4), 162-174 (2009). doi:10.1016/j.jconhyd.2009.04.010

Zhao, Z., Jing, L., Neretnieks, I.: Evaluation of hydrodynamic dispersion parameters in fractured rocks. J. Rock Mech. Geotech. Eng. 2(3), 243-254 (2010)

Zhao, Z., Jing, L., Neretnieks, I., Moreno, L.: Numerical modeling of stress effects on solute transport in fractured rocks. Comput. Geotech. 38, 113-126 (2011)

Zhao, Z.: Gouge particle evolution in a rock fracture undergoing shear: a microscopic DEM study. Rock Mech. Rock Eng. 46, 1461 (2013). doi:10.1007/s00603-013-0373-z

Zhou, Q., Liu, H.H., Molz, F.J., Zhang, Y., Bodvarsson, G.S.: Field-scale effective matrix diffusion coefficient for fractured rock: results from literature survey. J. Contam. Hydrol. 93(1-4), 161-187 (2007). doi:10. 1016/j.jconhyd.2007.02.002

Zimmerman, R.W., Al-Yaarubi, A., Pain, C.C., Grattoni, C.A.: Nonlinear regimes of fluid flow in rock fractures. Int. J. Rock Mech. Min. Sci. 41(3), 384-384 (2004)

Zimmerman, R.W., Bodvarsson, G.: Hydraulic conductivity of rock fractures. Transp. Porous Media 23, 1-30 (1996)

Zou, L., Jing, L., Cvetkovic, V.: Roughness decomposition and dynamic fluid flow in a single rock fracture. Int. J. Rock. Mech. Min. Sci. 75(2015), 102-118 (2015). doi:10.1016/j.ijrmms.2015.01.016

Zou, L., Jing, L., Cvetkovic, V. (2016a). Shear enhanced nonlinear flow in rough-walled rock fractures. Int. J. Rock Mech. Min. Sci. (under review)

Zou, L., Jing, L., Cvetkovic, V.: Assumptions of the analytical solution for solute transport in a fracture-matrix system. Int. J. Rock Mech. Min. Sci. 83, 211-217 (2016b) 